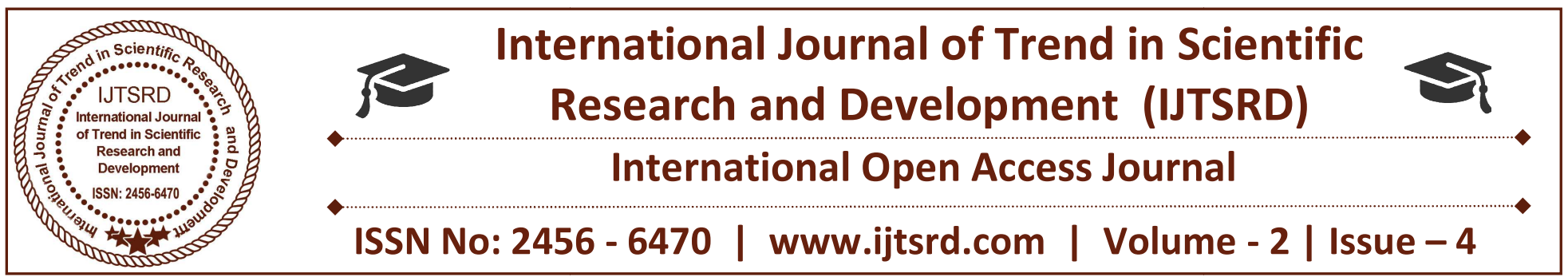

\title{
Mobile Application for the Agricultural Mandi using E-Auction
}

\author{
Ritesh Kumar Bista, Rahul Patidar, Manjunath C R \\ Department of Computer Science and Engineering, \\ School of Engineering and Technology, Jain University, Bengaluru, Karnataka, India
}

\section{ABSTRACT}

The Big Data analytics allude to the investigation of huge datasets gathered from different data sources, the Big Data plays very important role to discover extremely helpful data from the huge collection of datasets. The e-mandi business as of now utilizing the idea of Cloud Computing and Big Data especially to find helpful data. As an agrarian nation, India needs a created horticultural field, enabling the farmers and utilizing the advances, for example, e-agriculture, web-based promoting which can build up a solid economy. The proposed android e-auction system helps the famer to access the wide market portal across the world. This framework removes the problem of middlemen because of which famers don't get the right amount for their yield. So, through this framework farmers can sell their product through bidding system where there is possibility of getting very nice price for their product. The facilities of advertisement of the agricultural products, their worldwide marketing systems brings customer through every corner of the world. The paper centers around the Agricultural space especially Indian Agricultural framework which has been escaped these developing advancements, the proposed paper makes the utilization of Big Data Analytics to the agricultural area. The paper proposed show how farmers can utilize e-auction application to sell crops and provides various information about the generation subtle elements.

Keywords: Mandi, E-auction, Big data, eNAM, etc.

\section{INTRODUCTION}

The Indian agricultural system is the most essential area in the social and monetary development of our nation, in excess of 80 percent of the rural population relies upon the agricultural sector and the improvement of agricultural sector plays important part in the general nation's GDP, in the field of agricultural the utilization of ICT is constrained or nothing in a large portion of the spots, the agriculturists education rate, innovation reception is less before, however after the development of the Smartphone the farmer additionally getting to be techno savvy and appears to be ready to perform basic network and data operation on their cell phones, The utilization of web through Smartphone is expanding even in country put this gives us chance to make a structure which depends on ICT which will be valuable for the agriculturist .

Another issue here the greater part of them are straightforwardly connect to purchasers so the go between specialists not give the suitable cost to the farmers. Considering all such downside in the current framework the Big Data Analytics based Farmer Etrade proposed the component which will be basic and straightforward the farmer will be link to central information as cloud framework and every one of the information that possibly continuous advancement of their yield perhaps asked for from the ranchers and this data will be broke down utilizing different Big Data calculations to locate the suitable purchasers, the fundamental worry here the partners can see the state of harvest and have a thought of amount also .This basic structure should be set to deal with the whole lifecycle of the agrarian e-promoting. 
Big data analysis in agriculture is the next wave in innovation to help all part of our lives. In agriculture, information administration has long been perceived just like a chance to drive farm productivity. It is just through the improvement new tools in data capture and information sharing that such opportunities can be figured out. New innovation improvement in agriculture has moved from sensors and machines to methods in big data analysis. Data analytics can be used to avoid wastage by moving items faster and more efficiently. Which also helps analytics looking forward and back help with deciding the best crops to plant, thinking about both sustainability and benefit.

Generally, big data is characterized by the 5Vs:

Volume:

Volume refers to the amount of data collected. e.g., high-resolution and high-frequency of satellite and aerial imagery.

\section{Velocity:}

Velocity refers to the speed of data processing. e.g., real-time in-field cameras for monitoring plant growth.

$>$ Variety:

Variety refers to the large number of types of data and formats. e.g., traditional survey data vs. social media posts about food and food-borne illnesses.

$>$ Variability:

Inconsistency of the data set can hamper processes to handle and manage it.

$>$ Veracity:

The data quality of captured data can vary greatly, affecting the accurate analysis.

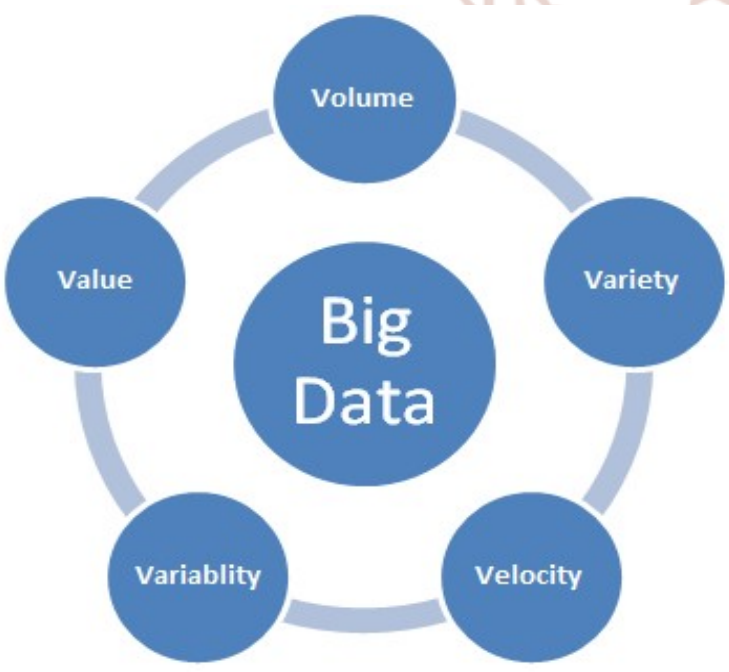

Fig 1.1: 5V's of Big Data

\section{Problem Statement}

eNAM is the abbreviation of Electronic National Agriculture Market, which is a virtual market with a physical market (mandi) at the back end, which arranges the current APMC/mandis to make a bound together national market for farming wares for container India electronic exchanging. The measuring of horticultural create at the market level is of most extreme significance to upgrade the attractiveness of the deliver and to empower the farmers to acknowledge value similar to the nature of their agricultural produce.

Mandis handles enormous volumes (parts) of landing and smaller parcels, consequently it is basic to give fast quality measuring arrangements (ideally inside a moment/parameter) to advance web based exchanging.

For this, the test is looking for development of fast reviewing and examining solution for eNAM which can likewise be associated with the web to build the productivity of the agrarian chain. Improvement of ecommercial centers to associate food processors with agripreneur/agriculturists to connect the esteem hole.

While independence in agriculture has been a need for the Government and a few arrangement activities weave around this target, the post-reap administration including farming advertising has not kept pace with the adjustments in economy, especially identifying with setting up of a proficient inventory network. The need to bind together market both at State and National level is, hence, essential to give better cost to farmers, enhance store network, decrease wastages and make a brought together national market for horticultural deliver. In such a situation, National Agriculture Market (NAM) would make a win-win circumstance for both i.e. agripreneurs and processors.

\section{Background Work}

The paper [1] proposed framework, National Agriculture Market which is a landmark initiative. This will help the farmer to sell their product on better option for sale and also could be able to access the wide market through warehouse based sale and also help farmers to transport their produce to the buyers. eNAM provides local trader to access the national market and for bulk transaction it provides access to the local mandi which decreases the intermediation cost. Hence by this it is also helping the rural economy and is also providing more employment in rural area. 
The Authors of paper [4] proposed one android based application or framework, named as - Krishi Ville which is basically for farmers. This mobile application handles all the updates of different agricultural commodities, news regarding agriculture and updates, updates of weather forecasting and various other activities.

The Authors of paper [10] mainly focus on the challenges of e-agriculture and its various possibilities in India's rural context. It incorporates certainties on Data asymmetry between farmers, districts and nations. In the paper, it depicts E-agriculture with the utilization of current Information and Communication Technologies (ICT).

The paper [16] describes about the demand and supply of agricultural products using technologies like clouds and grids. They discussed on various necessities and difficulties in designing such market called mandi. Their system architecture also helps to measure the mandi performance and estimating the overhead time of interaction between buyers and sellers.

\subsection{Existing system}

It essentially focused on coordinating 21 mandis in eight states; Uttar Pradesh, Gujarat, Telangana, Rajasthan, Madhya Pradesh, Haryana, Jharkhand and Himachal Pradesh. Propelled with a spending distribution of Rs. 200 crores, 25 key agro produces, including wheat, paddy, maize, onion, jowar, bajra, groundnut, potato, soyabean and mustard seed, were decided for e-trading. According to Press Information Bureau, Government of India, Ministry of Agriculture, 07-April-2017, up until now, 417 markets from 13 states have been incorporated with e-National Agriculture Market (e-NAM) against the set focus of 400 markets by March. What's more, according to the affirmed e/ - NAM Scheme, 585 controlled mandis the nation over are to be incorporated into the gateway by March 2018.

\subsection{Limitations of Existing system}

Even if the structure looks basic, for agriculturists, it may not be as straightforward of course. A large portion of the agriculturists has a convention of distributing their deliver to a nearby item aggregator at that point taking their crops to the mandis.

$>$ Even if a few farmers take them to mandis, their yield would be irrelevant to motivate far off purchasers offering on the web. In this situation, the likelihood of better value discovery is quite partial.

$>$ Quality contrasts in products at both the state and national level represent a challenge. For instance, wheat in Punjab and Haryana is of mid-range quality through those from Madhya Pradesh and Gujarat are of higher quality.

$>$ Electronic stages like NAM would be a correct stage just for exchange standardized products and for the rest it may not be.

$>$ Middlemen have a large margin of profit, thereby eating into the returns of farmers. Though consumers pay a fair price, farmers end up with paltry returns.

Mandi is a closed system. Everyone is not provided with the opportunity to sell in the mandi. As per the respective state APMC Acts, the admission of middlemen (aka sellers) are regulated. Mostly by prior registration cum licensing and few times by lottery, the sellers are allowed in Mandi. As everyone knows in this country, entry to Mandis as a seller involves a lot of bribery and lobbying. All these costs end up in eating consumers' pockets.

Mandi system doesn't provide credit lines to farmers during cultivation (like those Big MNC giants) and leave farmers in their tough period.

The existing system has a lot of deficiencies due to which small farmers are not getting sufficient income for their livelihood.

\section{Proposed System}

To overcome the issues in the current framework, we proposed a framework that removes the broker between farmer and market and farmers can apply new methods from the specialists through this framework. This framework gives stage to the agriculturists where they can know the costs of various markets and can offer their harvest for best cost. Our fundamental target is to make a system that incorporates the majority of our horticultural subjects and questions in a similar system where all the agricultural purposes can be possible effectively. In light of the need, the request determining for a specific harvest is done subsequently helping the agriculturist return better benefit. 


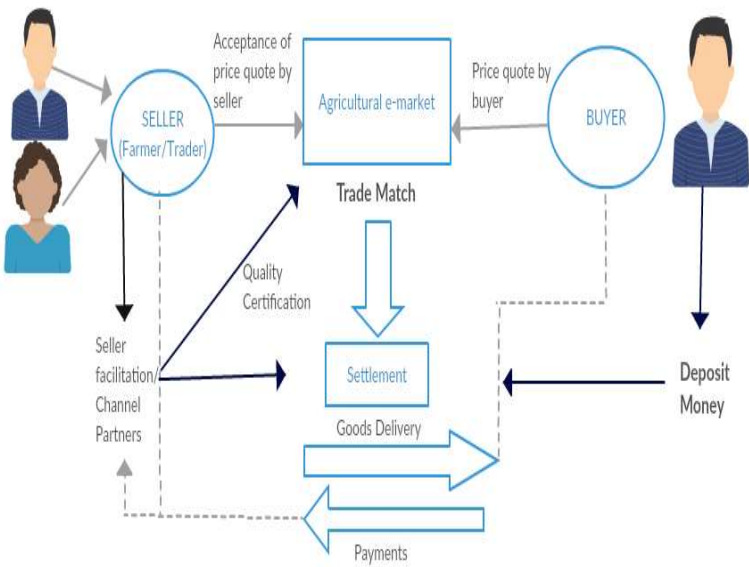

Fig 4: Workflow diagram

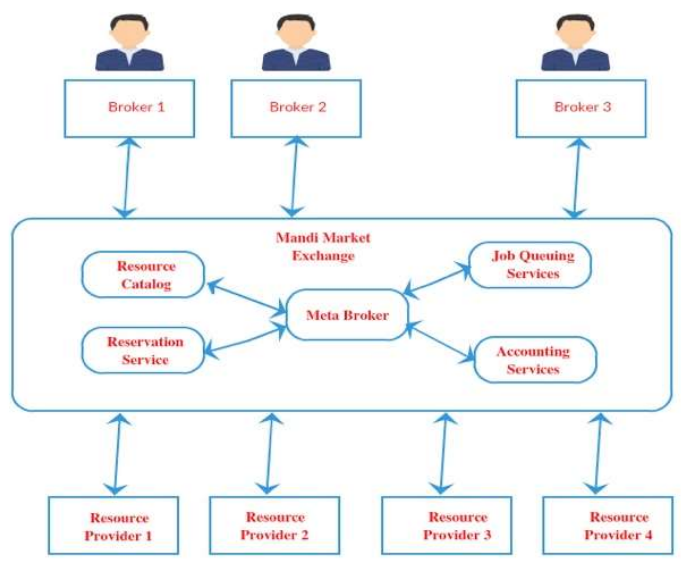

Fig 4.1: Trading Scenario

Agricultural e-mandi is an electronic trading portal 4.2 Module Design launched for the farmer's welfare to facilitate farmers, traders, buyers, exporters and processors with the common platform for trading commodities. The framework is managed by the farmers and other experts. Traders and exporters need to register with the framework to access the services provided by the trading portal.

\subsection{Trading Scenario}

The Figure demonstrates a run of the typical situation of exchanging directed inside Mandi. In the example given, Mandi led a double e-auction to coordinate offers of various asset solicitations to the suppliers inquire. To start with, the suppliers promote their assets with their cost (otherwise known as inquires). Purchasers present their offers to demonstrate their enthusiasm for renting the publicized assets. Every one of the offers and asks are put away in the database which will be gotten to toward the finish of the auction for ascertaining the triumphant offers. The MetaBroker, which is the primary specialist of Mandi, facilitates the coordinating of asks and offers, and exchanging between auction members. Toward the finish of the auction, the Meta-Broker chooses the winner and sends the reservation solicitations to the Reservation Service of Mandi. Then the Reservation Service illuminates the asset suppliers and consumers about the auction result. The data about reservations is put away inside Mandi utilizing the Accounting administration.
$>$ The idea is to develop an online bidding application that would help the farmers and the customers contact each other directly and do the business.

The online forum will help the customers interact with each other.

Farmers get to know the actual demand in the market through the requests that customers post on the application.

This application will be made available to anyone across the country via accessing the URL.
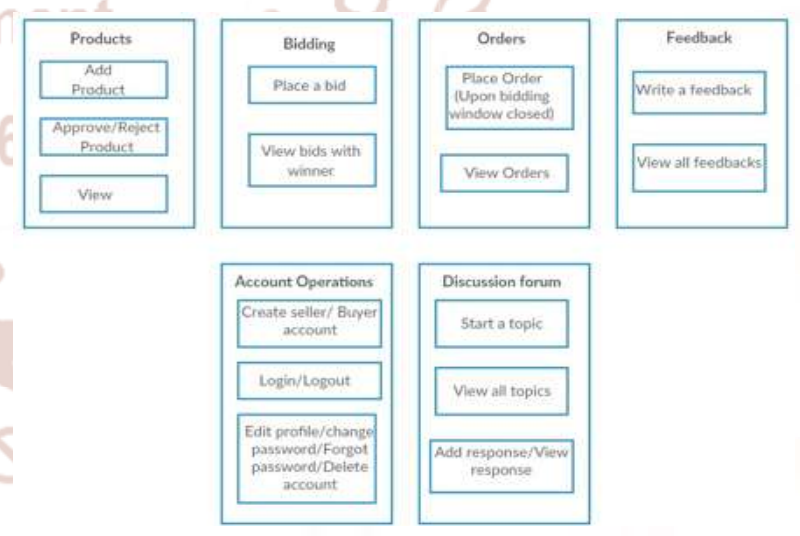

Fig 4.2: Module design

\subsection{Android Application Framework}

$>$ An Online Bidding application deployed on Cloud Platform as a Service (PaaS) for sales of agricultural products and deploys end to end live application feature.

$>$ The proposed system will be a mobile application using which the bidders (Buyers) and the sellers (Farmers) contact each other. They don't need to go anywhere. This application is available publicly to all the 
sellers, farmers and buyers across the country. Anyone can access this application and search bid on the products based on their requirements.

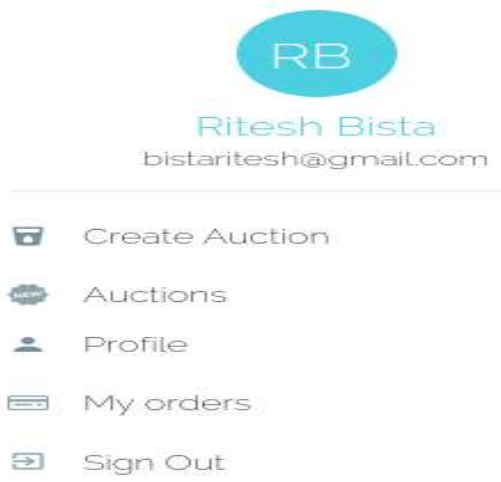

\subsubsection{Login and Signup Module}

Login and Signup module is used to register as buyer/seller. If you are already registered then enter the required details and sign in and start online trading but if you are a new user then you need to fill all the required details for trading purpose with the help of signup. In case if you forgot your user id or password then you can retrieve new password using your registered e-mail id.

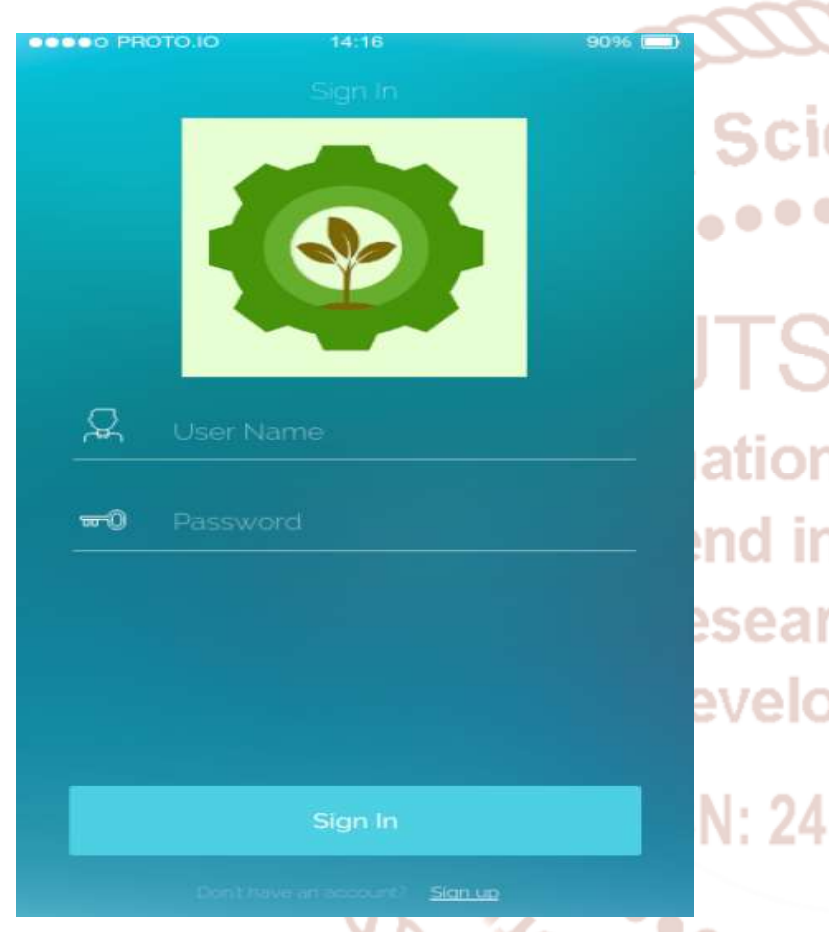

Fig 4.3.1: Login page

\subsubsection{Profile Module}

Profile module is used to view and update the buyers/seller's details. Using this module the user can check their orders through My Orders. They can also view their auction stats and also can create auction or can check active auctions present. And at-last there's sign out option for user to log out from the current session

\section{Fig 4.3.2: Profile page}

\subsubsection{Auction Module}

Auction details module is used by farmers/buyers based on their requirements. It has category option where you can choose category of your interest. Then enter the name of crop you want to sell and then mention quantity in $\mathrm{kg}$. Administrator has all the authority of fixing the base price based on the quality of the product. The buyer having the highest bid during the bidding duration will be declared as the winner and the product will be sold to that individual.

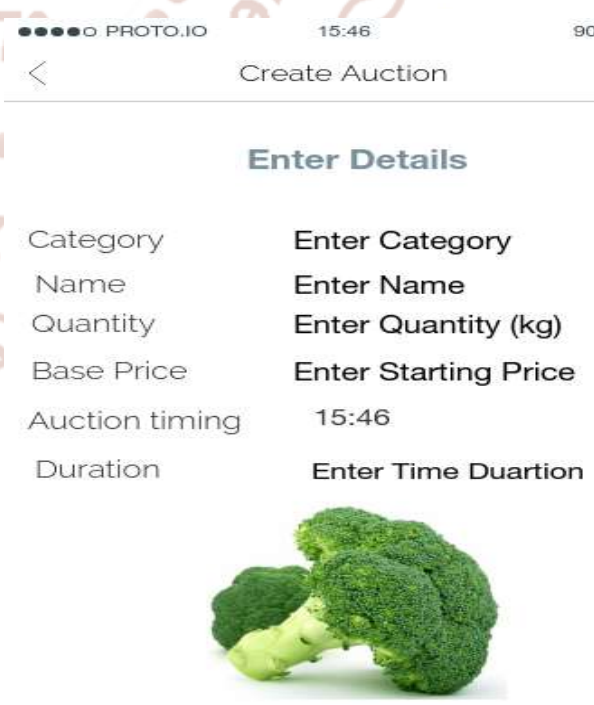

$$
\text { SUBMIT }
$$

Fig 4.3.3: Auction page 


\subsection{Features of the Proposed System}

With the help of big data performance tools, analyze the information in light of the need of area and kind of yield recommendation can be conveyed to farmers through this framework. The framework can contain features as specified:

$>$ Firstly, the promoting framework of agricultural items helps the farmer to offer their horticultural product with its related image from any place across the nation.

$>$ System can give farmers the approximate capacity of the cultivated items in any season along with the cultivation field's measure.

$>$ This framework can help farmers to know about different crop diseases and can get the remedy of the same from the experts.

$>$ The distinctive techniques for cultivation of various crops with new innovation to keep pace with the cutting-edge world.

$>$ The utilization of the different horticultural apparatuses, that is name, cost, offer place with the photo can arrive which will expand the nature of the instruments to the farmers so the agriculturists can develop more harvests.

$>$ At-last, the user of the application can also be allowed to access the daily news regarding the agriculture.

\subsection{Limitations of Proposed System}

The above proposed system has some of the challenges listed below which can be addressed.

$>$ The seller might not get best price for the product if there won't be many buyers to bid on because of which the product might go on less price.

$>$ Buyers might not be aware of the auction timing. As seller can create auction at any period of time.

$>$ Both buyers and sellers should be mobile friendly. If the user don't know how to use mobile it will be difficult to the user to use the application.

$>$ As it is online process, the users must be connected to the internet to access the auction and to buy/sell the product.

$>$ Required product might not be available on time as it depends upon the seller to which product he/she wants to sell.
$>$ Delivering the product might take some time depending upon the address of the buyer and seller.

\section{Conclusion}

As agricultural nation, we require a strong innovation and information base framework to keep pace with present day agribusiness of the world which will make our nation a really developed one. This online interface will help a considerable measure to develop our nation in an appropriate manner by removing poverty and creating the sources of self-employment for the large number of population of our nation with the assistance of present day science and innovation. It would help in expanding efficiency and in accomplishing objective of food security and comprehensive development in the nation. Moreover, these changes in agricultural market/will help India to address the difficulties postured by worldwide markets in the time of globalization and advancement.

\section{References}

1) J.P. Yadav, Abhishek Sharma, "National Agriculture Market: The Game Changer for Indian Farming Community", University of Rajasthan, Jaipur, IJSRM Volume 5 Issue 07 July 2017

2) Lucking-Reiley, David (2015), "Auctions on the Internet: What's Being Auctioned, and How?" Journal of Industrial Economics, 48(3): 227-52

3) Satish G. Athawale, Asst Prof., MGMs Institute of Management Aurangabad, Maharashtra (India), "APMC and E-trading for Financial Inclusiveness in Karnataka"

4) Manav Singhal, Kshitij Verma, Anupam Shukla, "Krishi Ville-Android based Solution for Indian Agriculture", Advanced Networks and Communication Systems(ANTS)2011, Bangalore ,26th 2nd November 2015, pp. 134-139.

5) Jie Wang, Shuo Yang, Yuezhi Wang and Cheng Han, "The Crawling and Analysis of Agricultural Products Big Data based on Jsoup", 12th International Conference on Fuzzy Systems and Knowledge Discovery (FSKD), 978-1-4673-7682$2 / 15$.

6) Anu Peisker and Soumya Dalai, "Data Analytics for Rural Development Indian Journal of Science and Technology", Vol 8(S4), 50-60, February 2015

7) Ch. Chandra Sekhar, Ch Sekhar, "Productivity improvement in agriculture sector using big data 
International Journal of Trend in Scientific Research and Development (IJTSRD) ISSN: 2456-6470

tools",2017 International Conference On Big Data Analytics and computational Intelligence (ICBDACI)

8) Wang Xiaoyu, Zheng Wensheng, Zheng Yaqin, "Under the Perspective of fresh agricultural products E-commerce supply chain model research," Journal of chongqing institute of technology (social science edition), vol.12, pp.6063, 2016.

9) Er. Rupinder Kaur, Raghu Garg, Dr. Himanshu Aggarwal, "Big Data Analytics Framework to Identify Crop Disease and Recommendation a Solution", 2016

10) Deka Ganesh Chandra, Dutta Borah Malaya, "Role of E-Agriculture in Rural Development in Indian Context", Emerging Trends in Networks and Computer Communication,20 11, Udaipur ,22nd 24th April 201 I, pp. 320-323, 201 I.

11) Purnima Shah, Deepak Hiremath and Sanjay Chaudhary, "Big Data Analytics Architecture for Agro Advisory System", 2016 IEEE 23rd International Conference on High Performance Computing Workshops
12) Aditya Saxena, Surendra Pratap Singh, Manju Rani, Manoj Kumar, "A Study of Crop Yield pattern with Climate Change based on Physical Parameters: Temperature and Rainfall in Western Uttar Pradesh to make future predictions for better Crop Management and Yield".

13) Mukesh kumar, Prof.Mayura nagar, "Big Data analytics in agriculture and distribution channel", Proceedings of the IEEE 2017 International Conference on Computing Methodologies and Communication (ICCMC), 978-1-5090-4890-8/17.

14) Ms. Nirali A. Kansagara, Ms.Trupti M. Khurape, Ms. Jyoti S. Kamble, Ms. Manasi M. Kulkarni, Prof. Mr. G.I. Rathod, "An Android Application for Online Agri-Auction" e-ISSN: 2395 -0056 Feb2016.

15) Guo, "A Study of the Application of Big Data in a Rural Comprehensive Information Service. Data Science Journal", 14: 12, pp. 1-8, 2015

16) Saurabh Kumar Garg.Christian Vecchiola. Rajkumar Buyya, "A market exchange for trading utility and cloud computing services" 